\title{
Design and Analysis of Multi-Phase BLDC Motors for Electric Vehicles
}

\author{
Gullu Boztas \\ Electrical and Electronics Engineering Dpt \\ University of Firat \\ Elazıg, Turkey \\ gboztas@firat.edu.tr
}

\author{
Merve Yildirim \\ Electrical and Electronics Engineering Dpt \\ University of Firat \\ Elazıg, Turkey \\ merveyildirim@firat.edu.tr
}

\author{
Omur Aydogmus \\ Mechatronics Engineering Dpt \\ University of Firat \\ Elazıg, Turkey \\ oaydogmus@firat.edu.tr
}

\begin{abstract}
This paper presents a design and analysis of multiphase brushless direct current (BLDC) motor for electric vehicles (EV). In this work, hub-wheels having $110 \mathrm{Nm}, 900 \mathrm{rpm}$ rated values have been designed for the proposed EV. This EV can produce $440 \mathrm{Nm}$ without using transmission, differential and other mechanical components which have very high losses due to the mechanical fraction. The motors to be used in the EV have been designed as 3-, 5- and 7-phase by Infolytica/Motor Solve Software to compare their performances at the same load conditions. The same rotor geometry has been utilized for the motors. However, slot numbers and dimensions of the stator have been determined by considering the motor phase number. Performance curves of phase-currents, output powers, torques, efficiencies and power factors have been presented for these motors at the same operating conditions. It can be possible to use lower power switches in motor drive system thanks to the phase current reduction since the phase currents decrease proportionally to motor phase number. This work shows that the multi-phase BLDC motors are a good alternative in order to obtain lower torque and lower power inverter structure than the 3-phase BLDC motors which are used as standard.
\end{abstract}

Keywords-brushless direct current motor; multi-phase motor; electric motor design

\section{INTRODUCTION}

Interest on electric vehicles (EV) has increased recently because of their environmental advantages, high energy efficiency, and low noise [1]. Significant properties of brushless direct current (BLDC) motors for EVs are high power density and high efficiency. Besides, there are important advantages such as small size, high reliability, not having rotor copper losses and low maintenance cost due to not having brushes [2, 3]. Therefore, BLDC motors are commonly preferred in industry applications. In [4], a novel five-phase wheel hub motor which occurs from identical electromagnetic units with U-shaped electromagnets in the stator and permanent magnets in the rotor is designed. The electromagnetic torque of the motor is calculated and analyzed by finite element method (FEM). Torque ripple, average torque, torque per ampere and the ratio of torque to copper loss are examined for optimal design and speed regulation. Authors in [5] propose a novel hub motor using variable electromagnetic (EM) gearing to leverage torque and rotation speed based on driving conditions. The performance of the motor in terms of voltage/current ratings and energy conversion efficiency is compared with other conventional motors. It is seen that this motor is useful for vehicle propulsion applications. Authors in [6] explain the design of permanent magnet (PM) BLDC hub motor using FEM analysis. The no-load and load characteristics are analyzed, torque and cogging torque of PM BLDC hub motor are calculated by Magnet Software 7.4.1 for different temperatures. Flux distribution and flux density in the core are also obtained. It is shown that PM BLDC hub motor can be used for applications including less cogging torque than total torque. In [7], a design of three phase PM BLDC hub motor which has high efficiency and power density and no cogging torque is realized for electrically powered two wheelers. Some methods are used to reduce the cogging torque and increase the net torque. PM BLDC motor is also analyzed by using 2D FEM. The simulation results are tested by experimental results. It is seen that PM BLDC hub motor has high efficiency and it is convenient for different scooter load and speed conditions.

In [8], field oriented control based on hall-effect sensors of PM brushless hub motor is defined for four-wheel drive EV. The aim of the study is to obtain high efficiency and low torque ripple by a feedforward controller. Results show that the feedforward field oriented control reduces the motor torque ripple. Ironless axial flux PM in-wheel hub motor is designed by using multi-domain FEM analysis [9]. 3D FEM analysis is realized in different physical domains showing temperature distribution, cooling system heat flows and the motor is tested experimentally. Results show that the designed in-wheel hub motor has high torque and high efficiency. Different control methods for PM brushless hub motor of four-wheel drive EV are defined in [10]. BLDC and PMSM control are combined. Since the performance of the sinusoidal current control is very good and the torque ripple is much lower than that of the block commutation algorithm, this control is preferred at low speeds. On the other hand, the noise is high at middle and high speeds due to switching and harmonics. Therefore, sinusoidal control or field oriented control and block commutation algorithm are used for low, middle and high speeds respectively. Results show that low noise and successful performance are obtained 
for four-wheel drive EV by the proposed approach. Feedforward and feedback speed regulation control of hub motor for EV with in-wheel motor is explained in [11]. The linear feedforward control with the incremental PID feedback control is realized and these control methods can be switched easily considering the driving demand and the running condition. It is obtained from the results that this control method provides a good speed regulation and shows the drivability of the in-wheel EV. The control methods of an EV driven by two rear hub motors are defined to examine the ride quality of EV in [12]. Vehicle dynamics with 11 degrees-offreedom are modeled by using MATLAB's Simulink. Simulations with PID controller, fuzzy-PID controller and without controller are realized and compared with each other. According to the simulations, these control methods improve yaw rate and the stability of the EV based on the steering and contribute to EVs with hub motors. In [13], computer aided design (CAD) of a PM BLDC hub motor is realized. Designed PM BLDC hub motor with $30 \mathrm{~W}, 48 \mathrm{~V}$, and $310 \mathrm{rpm}$ is used for a fan application. Flux density in the air gap and iron, stack length, slot space factor, length of the air gap and the number of the magnet poles are taken as design variables. Furthermore, the parametric analysis of BLDC hub motor is realized to develop the design in terms of the efficiency and size of the motor. By using FE analysis, designed algorithm is verified and the torque angle characteristics are obtained in the paper.

In this paper, three different BLDC motors have been designed for the comparison of motor performances based on the phase number. The slot numbers, dimension and geometry of the stator are changed to achieve a good comparison on the effect of the phase number. However, the rotor geometry of the compared motors is the same. It has been shown that the rated currents of the stator winding inversely decrease with the number of the phases. Thus, it can be possible to use lower power switches in the motor drive systems. The output power, efficiency and power factor remain as constant values for the compared motors in this study. As a result, it can be observed that increasing of the motor phase number is an advantage in terms of the motor quality. In this work, the pole number and the slot numbers of the designed motors have been taken as 24 and 27 (3-ph), 55 (5-ph), 63 (7-ph), respectively. Furthermore, torque and rated speed values of the motors are approximately $110 \mathrm{Nm}$ and $900 \mathrm{rpm}$, respectively.

\section{MODELING OF BLDC MOTOR}

In modeling of a 3-phase BLDC motor, armature winding and torque equations are used [14]. The equivalent circuit of BLDC motor having trapezoidal back EMF is shown in Figure 1. Back EMF and torque constant is a function of the rotor position. As seen in the Figure 1, the voltage equations within the armature windings based on the back EMF can be given by (1) $[14]$

$$
\left[\begin{array}{c}
V_{1} \\
V_{2} \\
: \\
: \\
V_{n}
\end{array}\right]=R \cdot\left[\begin{array}{c}
I_{1} \\
I_{2} \\
: \\
: \\
I_{n}
\end{array}\right]+L \cdot\left[\begin{array}{c}
\dot{I}_{1} \\
\dot{I}_{2} \\
: \\
: \\
\dot{I}_{n}
\end{array}\right]+\left[\begin{array}{c}
e_{1} \\
e_{2} \\
: \\
: \\
e_{n}
\end{array}\right]
$$

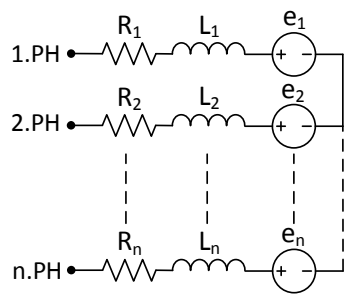

Fig. 1. BLDC equivalent circuit

where $\mathrm{n}$ is the phase number, $V_{1}, V_{2}, \ldots ., V_{n}$ are the supplied voltages to each phase $R$ is armature winding resistance, $I$ is phase current, $L$ is inductance and $e$ is back EMF.

There is a (360/n) phase angle between back EMFs of each phase as follows [14]

$$
\left[\begin{array}{c}
e_{1}(t) \\
e_{2}(t) \\
: \\
\vdots \\
e_{n}(t)
\end{array}\right]=\left[\begin{array}{c}
k_{e n}(\theta) \\
k_{e n}\left(\theta-\frac{2 \pi}{n}\right) \\
\vdots \\
\vdots \\
k_{e n}\left(\theta-\frac{2 \pi}{n}(n-1)\right)
\end{array}\right] . \omega(t)
$$

where $k_{e n}$ is back EMF constant of one phase of the n-phase motor.

Output torques of each phase are given by [14]:

$$
\left[\begin{array}{c}
T_{1}(t) \\
T_{2}(t) \\
: \\
: \\
T_{n}(t)
\end{array}\right]=\left[\begin{array}{c}
k_{T n}(\theta) \\
k_{T n}\left(\theta-\frac{2 \pi}{n}\right) \\
: \\
\vdots \\
k_{T n}\left(\theta-\frac{2 \pi}{n}(n-1)\right)
\end{array}\right] \cdot\left[\begin{array}{c}
I_{1}(t) \\
I_{2}(t) \\
: \\
: \\
I_{n}(t)
\end{array}\right]^{(-1)}
$$

where $k_{T n}$ is torque constant of a phase of the n-phase motor. Total output torque can be defined as

$$
T_{e}=T_{1}+T_{2}+\ldots+T_{n}
$$

where $T_{e}$ is total output torque.

\section{MULTI-PHASE MOTORS DESIGN}

In motor design, nominal speed and torque values should be firstly determined. According to these two parameters, motor mechanical restrictions like motor dimension should be taken into consideration. It is also important to obtain a geometry for reducing torque ripples. Generally, torque ripples can be reduced by increasing the BLDC pole number. In this paper, three different motors have been designed: 3-phase, 5-phase and 7-phase. Designed motors structure is shown in Figure 2, in which while stator forms the interior of the motor, rotor is the outer of the motor. Stator and rotor structures and flux lines and flux densities of BLDC motors designed for different phases are shown in Figures 3 and 4, respectively. Flux lines and flux density of the three motors are illustrated in Figure 4. 
Maximum flux density obtained from stator core has been calculated as $1.94 \mathrm{~T}$.

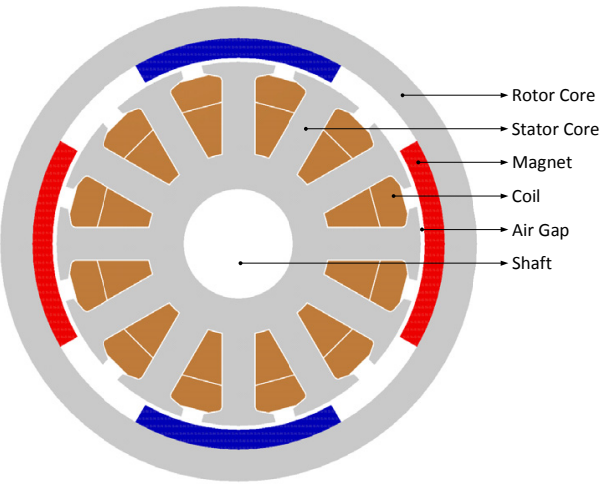

Fig. 2. BLDC hub-motor structure

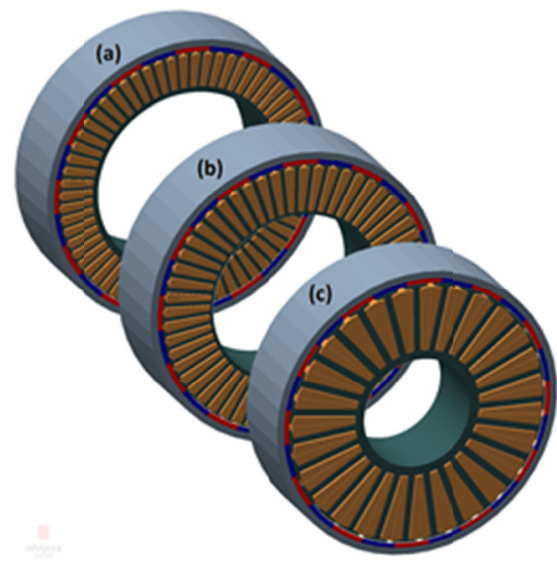

Fig. 3. Stator/rotor structures of the designed motors: a) 7-ph, b) 5-ph, c) 3 -ph

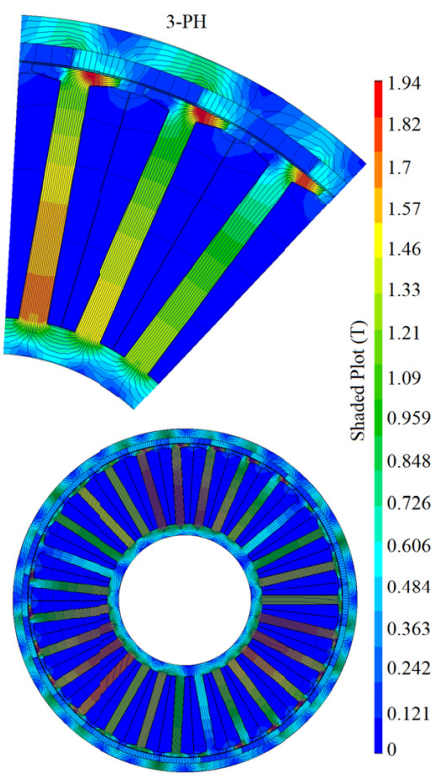

(a)

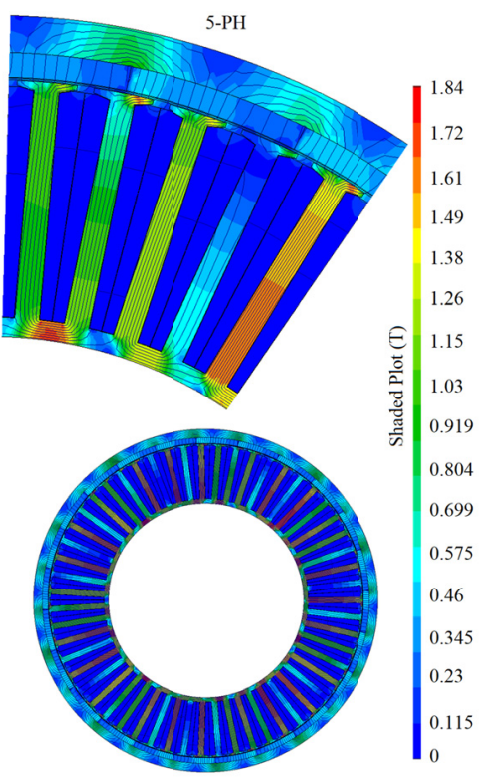

(b)

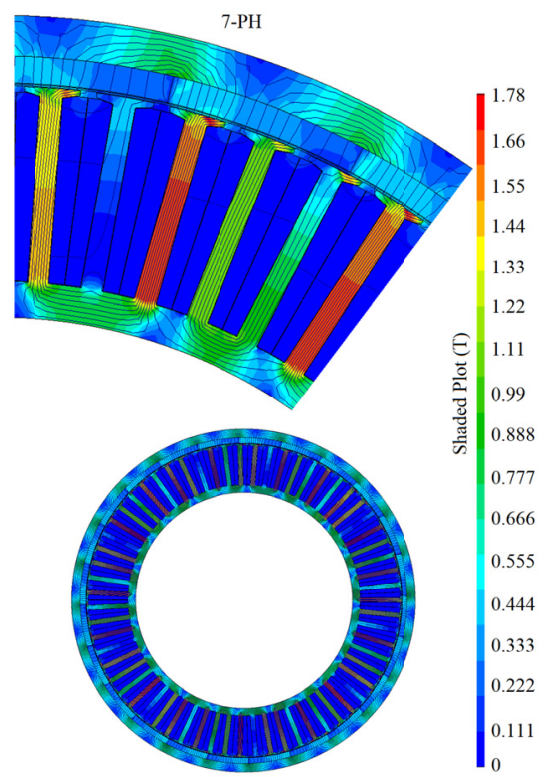

(c)

Fig. 4. Flux lines and flux density of the motors; a) 3-ph, b) 5-ph, a) 7-ph

The designed motors have the same rotor structure as surface mounted with radial magnets per pole and their inner and outer rotor diameters have been taken as equal. Their only difference is the number of slots and the slot dimensions. More stator slot area is needed for lower phase number, since phase current value changes inversely with the phase number. Therefore, more coil area is obtained by reducing the number of the slot of 3-phase BLDC motor. The numbers of the slots in the designed motors are 27, 55, and 63 for 3, 5, and 7-phases respectively.

Mechanical and electrical parameters of BLDC motors are illustrated in Table I. As shown in Table I, stator phase currents significantly reduce inversely with the phase number. Thus, lower phase current will be obtained by increasing the phase number. In this way, both cost and size will reduce by decreasing the rated current values of semi-conductor switches to be used in drive. BLDC motors have been designed to have equal output powers and torques.

\section{MULTI-PHASE MOTOR ANALYSIS}

The ability of the motor to provide maximum torque up to the rated speed range is one of the important results in BLDC motor design. Torque-speed curves of the designed BLDC motors are shown in Figure 5. These motors produce $110 \mathrm{Nm}$ torque in steady-state situation. PWM analyses of 3-phase BLDC motor are given in Figure 6. The motor ensures the maximum power and efficiency when the motor reaches the rated speed. The efficiency of the BLDC motor is approximately obtained as $90 \%$ in the region above $50 \%$ speed. 
Motor output power has increased to $10.3 \mathrm{~kW}$. Power factor has been calculated as 0.58 under full load conditions.

TABLE I. DESIGNED MOTOR PARAMETERS

\begin{tabular}{|c|c|c|c|}
\hline Designed Motors & 3-phase & 5-phase & 7-phase \\
\hline Supply Voltage (V) & 96 & 96 & 96 \\
\hline Rated Current (A) & 164 & 102 & 70 \\
\hline Number of slots & 27 & 55 & 63 \\
\hline Rotor outer diameter (mm) & 300 & 300 & 300 \\
\hline Stack height (mm) & 80 & 80 & 80 \\
\hline Stator outer diameter (mm) & 274 & 274 & 274 \\
\hline Stator inner diameter (mm) & 115 & 170 & 189 \\
\hline
\end{tabular}

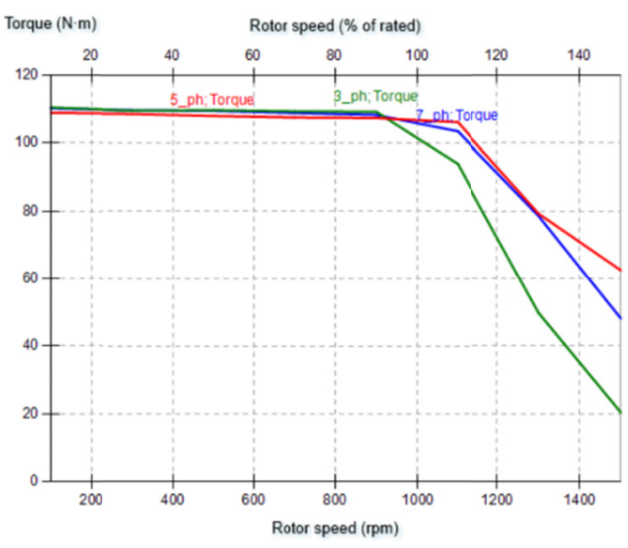

Fig. 5. Torque-speed curves of the designed motors

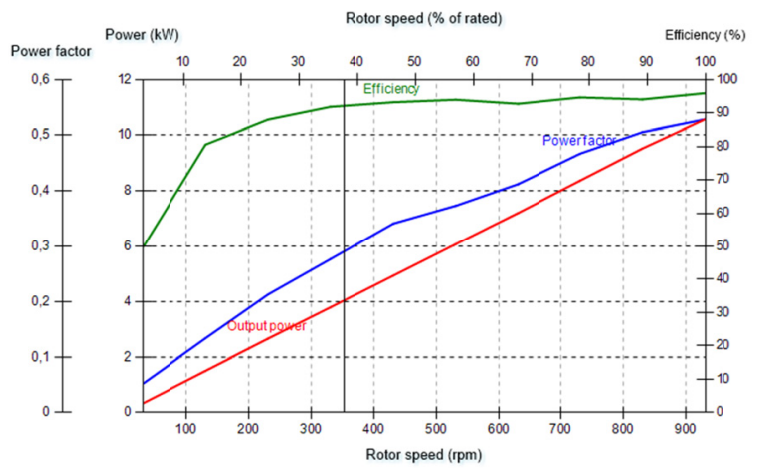

Fig. 6. PWM analysis for 3-phase motor

PWM analysis of 5-phase motor is realized in Figure 7. As seen from the Figures 6 and 7, the performance of 5-phase BLDC motor in low speeds is worse than that of the 3-phase BLDC motor. At $100 \mathrm{rpm}$ speed, the efficiency of 5-phase motor is lower than $71 \%$ while the efficiency of the 3-phase motor is approximately $82 \%$. However, the performances of the motors towards rated speeds are significantly similar. Same performance analysis is realized for 7-phase motor and illustrated in Figure 8. Desired performance from 7-phase motor is also obtained like the other motors. The output power, efficiency and power factor of the motors are given in Table-II for low and high speed regions. Stator phase currents of the BLDC motors are shown in Figure 9. Current values are inversely proportional to the number of the phase. The rms values of the motor currents are 164A (3-ph), 102A (5-ph) and 70A (7-ph) respectively.

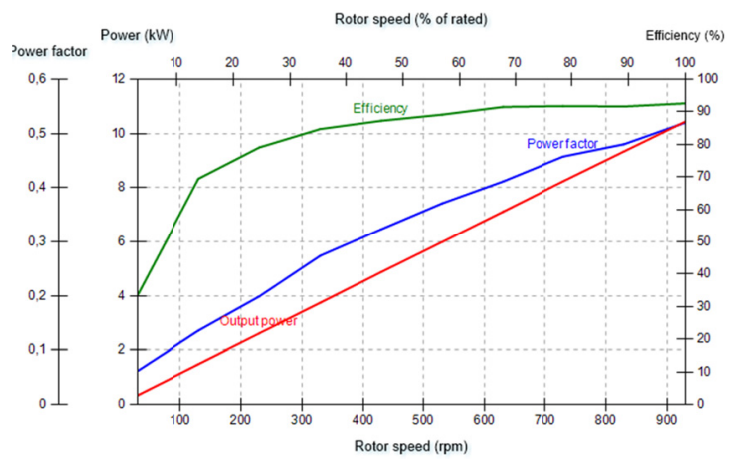

Fig. 7. PWM analysis for 5-phase motor

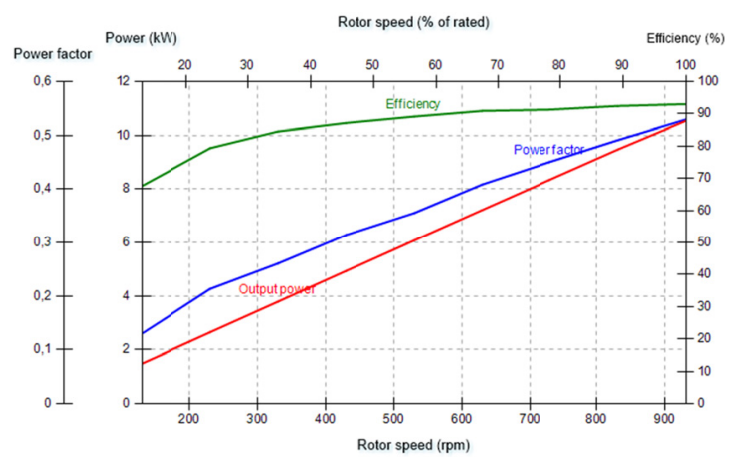

Fig. 8. PWM analysis for 7-phase motor

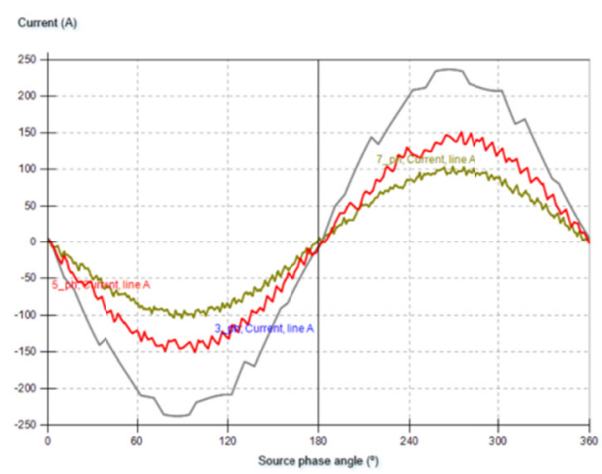

Fig. 9. Stator phase currents of the designed motors

TABLE II. COMPARISONS FOR LOW/HIGH SPEED REGIONS

\begin{tabular}{|c|c|c|c|c|c|c|}
\hline \multirow{2}{*}{$\begin{array}{c}\text { Phase } \\
\text { Number }\end{array}$} & \multicolumn{3}{|c|}{$\begin{array}{c}\text { Low Speed Region } \\
\text { (150 rpm) }\end{array}$} & \multicolumn{3}{|c|}{$\begin{array}{c}\text { High Speed Region } \\
\text { (900 rpm) }\end{array}$} \\
\cline { 2 - 7 } & $\begin{array}{c}\mathbf{P}_{\text {out }} \\
(\mathbf{k W})\end{array}$ & $\begin{array}{c}\text { Eff. } \\
\mathbf{( \% )}\end{array}$ & $\mathbf{P F}$ & $\begin{array}{c}\mathbf{P}_{\text {out }} \\
(\mathbf{k W})\end{array}$ & $\begin{array}{c}\text { Eff. } \\
\mathbf{( \% )}\end{array}$ & PF \\
\hline 3 & 1.8 & 82 & 0.15 & 10.3 & 95 & 0.58 \\
\hline 5 & 1.8 & 71 & 0.15 & 10.1 & 92 & 0.51 \\
\hline 7 & 1.8 & 70 & 0.15 & 10.1 & 92 & 0.51 \\
\hline
\end{tabular}

The output torque curve is separately examined for the three motors in Figure 10. The torque ripples of 3-, 5- and 7phase motors are approximately $10 \%, 5 \%$ and $6 \%$ respectively. As the number of phases increases, torque ripple reduces. However, as seen in Figure 10, the result obtained by the 5phase motor can be regarded as sufficient. Hence, increasing the phase number by more than 5 is useful only for reducing the stator currents. 


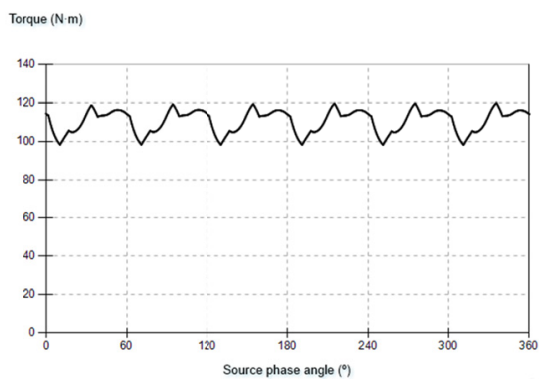

(a)

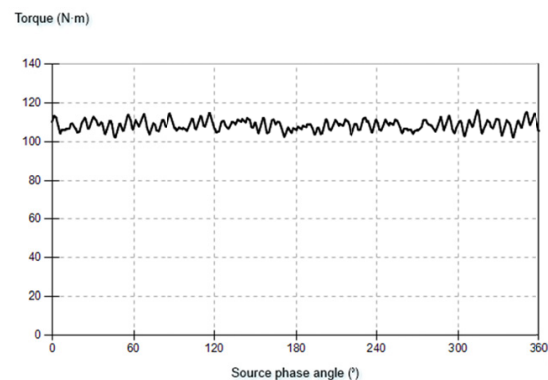

(b)

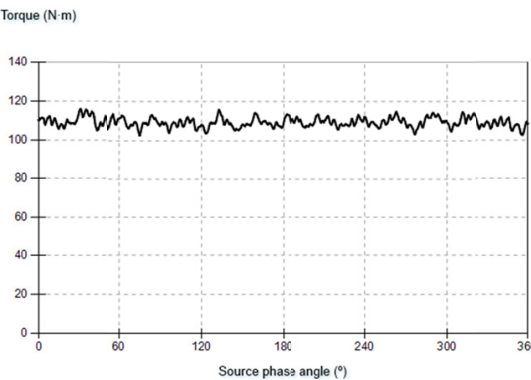

(c)

Fig. 10. Output torque at steady-state conditions; a) 3-phase BLDC, b) 5-phase BLDC, c) 7-phase BLDC

\section{CONCLUSIONS}

In this study three motors have been designed in order to focus on comparing the effect of the phase number on motor. These motors used as wheel in EVs are called hub motors. Firstly, a 3-phase BLDC hub motor is designed as a base motor. This motor has inner stator and outer rotor structures. Then, 5-phase and 7-phase motors having the same rotor dimensions of the base motor have been designed. The number of the slots and dimensions of the stator have been determined by considering the motor phase number. The performance analyses of the 3-, 5-, and 7-phase motors have been obtained by Infolytica/Motor Solve Software package. Performance curves of phase-currents, output powers, torques, efficiencies and power factors have been presented for these motors at the same operating conditions. According to the results, it is observed that as the number of the phases of the motor increases, the phase currents reduce. This allows the use of lower power switches in motor driving systems. This work shows that multi-phase BLDC motors are a good alternative in order to use lower power inverter structure compared with 3phase BLDC motors that are used as standard. Output torque and power values have been calculated as $110 \mathrm{Nm}, 10.3 \mathrm{~kW}$ in designed motors. By considering the use of four wheels for an $\mathrm{EV}$, total output torque and output power have approximately been obtained as $440 \mathrm{Nm}$ and $41.2 \mathrm{~kW}$ in the designed motors. The other important characteristic for BLDC motors is the output torque curve. As the number of the motor phase increases, the torque ripple produced by the motors significantly reduces. However, torque ripples of the 5-phase motor are lower than that of other motors. Therefore, the motor phase number should be evaluated in terms of cost, performance and usability when considered commercially.

\section{REFERENCES}

[1] X. Fu, "A novel design for flywheel battery of electric vehicles", IEEE International Conference on Intelligent System Design and Engineering Application, Changsha, China, Vol. 1, pp. 107-111, October 13-14, 2010

[2] M. Yildirim, M. Polat, H. Kurum, "A survey on comparison of electric motor types and drives used for electric vehicles", IEEE 16th International Power Electronics and Motion Control Conference and Exposition, Antalya, Turkey, pp. 218-223, September 21-24, 2014

[3] S. M. Jang, H. W. Cho, S. K. Choi, "Design and analysis of a high-speed brushless DC motor for centrifugal compressor", IEEE Transactions on Magnetics, Vol. 43, No. 6, pp. 2573-2575, 2007

[4] C. Sun, L. Bai, X. Du, Y. Zhou, "A novel wheel hub motor based on Ushaped electromagnet working principle and torque characteristics", IEEE 9th Conference on Industrial Electronics and Applications, Hangzhou, China, pp. 1398-1403, June 9-11, 2014
[5] M. T. Peng, S. H. Chien, Y. C. Chung, T. S. Liu, T. J. Flack, "A novel high-torque-density and wide-speed-range hub motor for electric vehicle propulsion", IEEE Electric Vehicle Symposium and Exhibition, Barcelona, Spain, November 17-20, 2013

[6] S. Abirami, S. M. Bala, R. J. Priya, "Design of BLDC hub motor using FEM analysis", IEEE International Conference on Green Computing Communication and Electrical Engineering, Coimbatore, India, March 6-8, 2014

[7] S. Ekram, D. Mahajan, M. Fazil, V. Patwardhan, N. Ravi, "Design optimization of brushless permanent magnet hub motor drive using FEA", International Conference on Electrical Machines and Systems, Seoul, South Korea, pp. 1476-1480, October 8-11, 2007

[8] D. Lu, J. Li, J. Gu, "Field oriented control of permanent magnet brushless hub motor in four-wheel drive electric vehicle", 8th International Conference on Future Generation Communication and Networking, Haikou, China, pp. 128-131, December 20-23, 2014

[9] O. Winter, S. Ucsnik, M. Rudolph, C. Kral, E. Schmidt, "Ironless inwheel hub motor design by using multi-domain finite element analyses", International Symposium on Power Electronics, Electrical Drives, Automation and Motion, Sorrento, Italy, pp. 1474-1478, June 20-22, 2012

[10] D. Lu, J. Li, M. Ouyang, J. Gu, "Research on hub motor control of fourwheel drive electric vehicle", IEEE Vehicle Power and Propulsion Conference, Chicago, USA, September 6-9, 2011

[11] H. Yu M. Huang, "Speed regulation control combining feedforward with feedback of hub motor for motor-wheel driving electric vehicle", International Conference on Electrical and Control Engineering, Yichang, China, pp. 4976-4979, September 16-18, 2011

[12] Y. Chen, Z. Lu, "Study on control of an two hub-motor electric vehicle", IEEE International Conference on Information and Automation, Harbin, China, pp. 627-632, June 20-23, 2010

[13] K. R. Rajagopal, C. Sathaiah, "Computer aided design and FE analysis of a PM BLDG hub motor", International Conference on Power Electronics, Drives and Energy Systems, New Delhi, India, December 12-15, 2006

[14] Y. S. Jeon, H. S. Mok, G. H. Choe, D. K. Kim, J. S. Ryu, "A new simulation model of BLDC motor with real back EMF waveform", The 7th Workshop on Computers in Power Electronics, Blacksburg, USA, pp. 217-220, July $16-18,2000$ 